\title{
Correlation of Six Minute Walk Test with Spirometry Indices in Chronic Obstructive Pulmonary Disease Patients
}

\author{
Shanmuga Priya K. ${ }^{1}$, Prasanth G. ${ }^{2}$, Aarthi R. ${ }^{3}$, Rosheeni R. ${ }^{4}$, Abdul Majeed Arshad ${ }^{5}$, Rajagopalan B. ${ }^{6}$
}

\begin{abstract}
${ }^{1}$ Department of Pulmonary Medicine, Sri Ramachandra Institute of Higher Education and Research, Chennai, Tamilnadu, India. ${ }^{2}$ Department of Pulmonary Medicine, Sri Ramachandra Institute of Higher Education and Research, Chennai, Tamilnadu, India. ${ }^{3}$ Department of Pulmonary Medicine, Sri Ramachandra Institute of Higher Education and

Research, Chennai, Tamilnadu, India. ${ }^{4}$ Department of Pulmonary Medicine, Sri Ramachandra Institute of Higher Education and Research, Chennai, Tamilnadu, India. ${ }^{5}$ Department of Pulmonary Medicine, Sri Ramachandra Institute of Higher Education and Research, Chennai, Tamilnadu, India. ${ }^{6}$ Department of Pulmonary Medicine, Sri Ramachandra Institute of Higher Education and Research, Chennai, Tamilnadu, India.
\end{abstract}

\section{ABSTRACT}

\section{BACKGROUND}

Spirometry is the gold standard for accurate measurement of lung function. However, it is only one way of interpreting COPD disease severity and is effort dependent. Measurement of Peak Expiratory Flow Rate, 6-minute walk test (6-MWT) and quantitative assessment of symptoms like MMRC dyspnoea scale offers cheaper modes of assessing lung function. Six Minute Walk Test is the most commonly used test for assessing the functional capacity of persons with Chronic Obstructive Pulmonary Disease. It is a reliable, repeatable, reproducible and responsive test for measuring the functional exercise capacity of patients with Chronic Obstructive Pulmonary Disease.

\section{METHODS}

It is an observational study conducted in South Indian tertiary care hospital. All consecutive patients with confirmed diagnosis of chronic pulmonary disease attending the department of pulmonology, Sri Ramachandra Institute of Higher Education and Research, from January 2018 to January 2019, were included in the study. Six Minute Walk Test and Spirometry were performed as per American Thoracic Society guidelines. Correlation between Six Minute Walk Test and Spirometry was assessed using statistical software, Statistical Package for Social Sciences (SPSS) version 16.0.

\section{RESULTS}

The variables of Six Minute Walk test like six-minute walk distance and six-minute distance saturation both correlated positively with Spirometry parameters FVC, FEV1, FVC/FEV1 in COPD patients. In this study, we demonstrated that six minute walk test significantly correlated with absolute values of Spirometry. Six Minute Walk Test can replace spirometry in assessment of severity of Chronic Obstructive Pulmonary Disease.

\section{CONCLUSIONS}

Six Minute Walk Test significantly correlated with absolute spirometry values of FEV1/FVC, FVC, FEV1. Thus, we conclude that Six Minute Walk Test can replace spirometry in assessment of severity of Chronic Obstructive Pulmonary Disease. The variables of six-minute walk test varied as the severities of the disease varied. The six-minute walk distance and six-minute distance saturation both correlated with Spirometry parameters FVC/FEV1 (moderate positive correlation or weak positive correlation) in severe, very severe Chronic Obstructive Pulmonary Disease patients and $\mathrm{SpO}_{2}$ correlated with the scale. The predicted percent of FVC/FEV1 and FVC correlated with six-minute walk distance saturation in meters.

\section{KEY WORDS}

Six Minute Walk Test, 6MWT, Spirometry, PFT, COPD

\author{
Corresponding Author: \\ Dr. Shanmuga Priya K. \\ No. 5, M. P. Avenue, Majestic Colony, \\ Saligramam, Chennai-600093, \\ Tamilnadu, India. \\ E-mail: pshanmuga75@yahoo.com
}

DOI: $10.14260 / \mathrm{jemds} / 2019 / 812$

Financial or Other Competing Interests: None.

How to Cite This Article:

Priya SK, Prasanth G, Aarthi $R$, et al. Correlation of six minute walk test with spirometry indices in chronic obstructive pulmonary disease patients. J. Evolution Med. Dent. Sci. 2019;8(50):3749-3753, DOI: 10.14260/jemds/2019/812

Submission 29-03-2019, Peer Review 27-11-2019, Acceptance 04-12-2019, Published 16-12-2019.

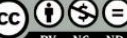




\section{BACKGROUND}

Chronic Obstructive Pulmonary Disease (COPD) is a common, preventable and treatable disease that is characterized by persistent respiratory symptoms and airflow limitation that is due to airway and/or alveolar abnormalities usually caused by significant exposure to noxious particles or gases. Chronic Obstructive Pulmonary Disease (COPD) is currently the fourth leading cause of death in the world, ${ }^{1}$ but is projected to be the $3^{\text {rd }}$ leading cause of death by 2020 .

Spirometry is the most reproducible and objective measurement of airflow limitation. It is a noninvasive and readily available test. Despite its good sensitivity, peak expiratory flow measurement alone cannot be reliably used as the only diagnostic test because of its weak specificity. ${ }^{2}$ Spirometry is used to evaluate dyspnoea, respiratory impairment, and operative risk, detect obstructive airway disease like Chronic Obstructive Lung disease and Bronchial Asthma, establish baseline lung function, and monitor effects of therapies used to treat respiratory disease, detect upper airways defects like tracheal stenosis and perform surveillance for occupational-related lung disease. Spirometry measurements are evaluated by comparison with reference values ${ }^{3}$ based on age, height, sex, and race. Spirometry should measure the volume of air forcibly exhaled from the point of maximal inspiration (Forced vital capacity, FVC) and the volume of air exhaled during the first second of this maneuver (Forced expiratory volume in one second, $\mathrm{FEV}_{1}$ ), and the ratio of these two measurements (FEV $1 / F V C$ ) should be calculated. The spirometric criterion for airflow limitation remains a post-bronchodilator fixed ratio of $\mathrm{FEV}_{1} / \mathrm{FVC}<0.70$. There is disproportionate reduction in the FEV 1 as compared to the FVC which is reflected in the $\mathrm{FEV}_{1} / \mathrm{FVC}$ ratio and is the hallmark of obstructive lung diseases. The American Thoracic Society (ATS) defines acceptable spirometry as an expiratory effort that has the following characteristics like Starts from full inflation, Shows minimal hesitation at the start of the forced expiration (extrapolated volume (EV) $<5 \%$ of FVC or $0.15 \mathrm{~L}$, whichever is larger), Shows an explosive start of the forced exhalation (time to peak flow no greater than $0.12 \mathrm{~s}$ ), Shows no evidence of cough in the first second of forced exhalation, Meets one of three criteria that define a valid end-of-test: (1) smooth curvilinear rise of the volume-time tracing to a plateau of at least 1 second's duration; (2) if a test fails to exhibit an expiratory plateau, a forced expiratory time (FET) of 15 seconds; or (3) when the patient cannot or should not continue forced exhalation for valid medical reason. Patients with active tuberculosis should not be tested. Relative contraindications for spirometry include recent abdominal or thoracic surgical procedures, recent eye surgery, haemoptysis of unknown origin, pneumothorax, unstable angina pectoris, recent myocardial infarction and thoracic, abdominal or cerebral aneurysms.

The six-minute walk test (6mwt) is a test that can aid in assessing the functional capacity of patients with cardiopulmonary disease. Six Minute Walk Test (Six Minute Walk Test), is used as a clinical indicator of the functional capacity in COPD patients ${ }^{4}$. It is an objective method to measure the ability to perform daily living activities. Six Minute Walk Test (Six Minute Walk Test) is a reproducible, simple and inexpensive test ${ }^{5}$. To reduce the variability between test subjects and to improve the reproducibility in a given individual, the test standard specifies that Six Minute Walk Test must be conducted on a $30 \mathrm{~m}$ straight path. Pretest assessment should include resting Oxygen saturation $\left(\mathrm{SpO}_{2}\right)$, heart rate, blood pressure, baseline dyspnoea and Respiratory rate. Patient was asked to walk at their own pace for as much distance as possible in 6 minutes and allowed to stop if they developed dyspnoea, chest pain or leg cramps. The test was discontinued if the patient experienced any chest pain, severe dyspnoea, saturation drop or if the patient wanted to quit due to any reason. The Six Minute Walk Test measures four functional indicators: 6-minute walking distance (6MWD), self- perceived dyspnoea, oxygen saturation and heart rate at the end of test. Repeat testing should be done at the same time of the day to reduce intraday variability. Absolute contraindications include the following: Room air $\mathrm{SpO}_{2}$ at rest less than 85\%, Thrombosis of lower extremities,, Acute pulmonary embolus or pulmonary infarction, Suspected dissecting aneurysm, Acute myocardial infarction, Unstable angina, Uncontrolled arrhythmias causing symptoms or hemodynamic compromise, Active endocarditis, Acute myocarditis or pericarditis, Symptomatic severe aortic stenosis, Uncontrolled heart failure, Pulmonary oedema, Acute respiratory failure, Acute non cardiopulmonary disorder that may affect exercise performance or be aggravated by exercise, Mental impairment leading to inability to cooperate.

We wanted to correlate variables of six minute walk test like six minute walk distance and six minute distance saturation with various spirometry indices like FEV1/FVC, FEV1, and FVC in patients with Chronic Obstructive Pulmonary Disease.

\section{METHODS}

It is an observational study conducted in a tertiary care hospital. Consecutive patients with proven COPD by spirometric diagnosis (post bronchodilator FEV1/FVC, $<70 \%$ ) attending the department of pulmonology, Sri Ramachandra Institute of Higher Education and Research from January 2018 to January 2019 were included in the study. The study included 30 spirometry confirmed COPD patients defined by the GOLD criteria. They underwent HRQoL measurement using the disease-specific (SGRQ). functional exercise capacity measured by Six Minute Walk Test, as per American Thoracic Society (ATS) guidelines. Pulmonary function test were conducted as per ATS recommendation using computerized flow sensing spirometer with Helios software. Patient was given proper instruction before and during the test. The test was repeated after 15 minutes administration of short acting beta 2 agonist (salbutamol). Exhalation time was at least 6 seconds and the end of the test was indicated by a 2-volume plateau. Spirometric indices according to ATS criteria including Forced Expiratory Volume in $1^{\text {st }}$ second (FEV1), Forced Vital Capacity (FVC), FEV1/FVC ratio were calculated for each patient by doing at least three measurements for each lung function and the predicted values were calculated with highest values being accepted. The age, sex, weight, height and BMI of patients were recorded prior to Six Minute Walk Test. Six Minute Walk Test was performed in 30-m long and 
ventilated indoor corridor according to ATS guidelines. At start of the test Heart Rate, Respiratory Rate Blood Pressure, oxygen saturation $\left(\mathrm{SpO}_{2}\right)$ of patient using pulse oximetry were measured. Patient was asked to walk at their own pace for as much distance as possible in 6 minutes and allowed to stop if they developed dyspnoea, chest pain or leg cramps. Test was continued as soon as possible if the patient was able to walk again. The test was discontinued if the patient experienced any chest pain, severe dyspnoea, saturation drop or if the patient wanted to quit due to any reason. And at end of the test Heart rate, Respiratory rate Blood Pressure, oxygen saturation $\left(\mathrm{SpO}_{2}\right)$ were reassessed. The distance walked for 6 minutes (Six minute walk distance) were recorded in meters and BODE index consisting of BMI were calculated. The patients were observed to assess any possible complications for 15 minutes after the test

\section{Statistical Analysis}

Data of was sorted, coded and entered into the computer using statistical software, Statistical Package for Social Sciences (SPSS) version 16.0. We presented the quantitative variables, mean, standard deviation was calculated for descriptive statistics. The Pearson correlation coefficient test was done to assess the association between those variables of six-minute walk test and spirometry indices. A p value $<0.05$, was considered statistically significant.

\section{RESULTS}

The variables of Six Minute Walk test like six-minute walk distance and six-minute distance saturation both correlated positively with Spirometry parameters FVC, FEV1, FVC/FEV1 in COPD patients. In this study we demonstrated that six minute walk test significantly correlated with absolute values of Spirometry. Six Minute Walk Test can replace spirometry in assessment of severity of Chronic Obstructive Pulmonary Disease.
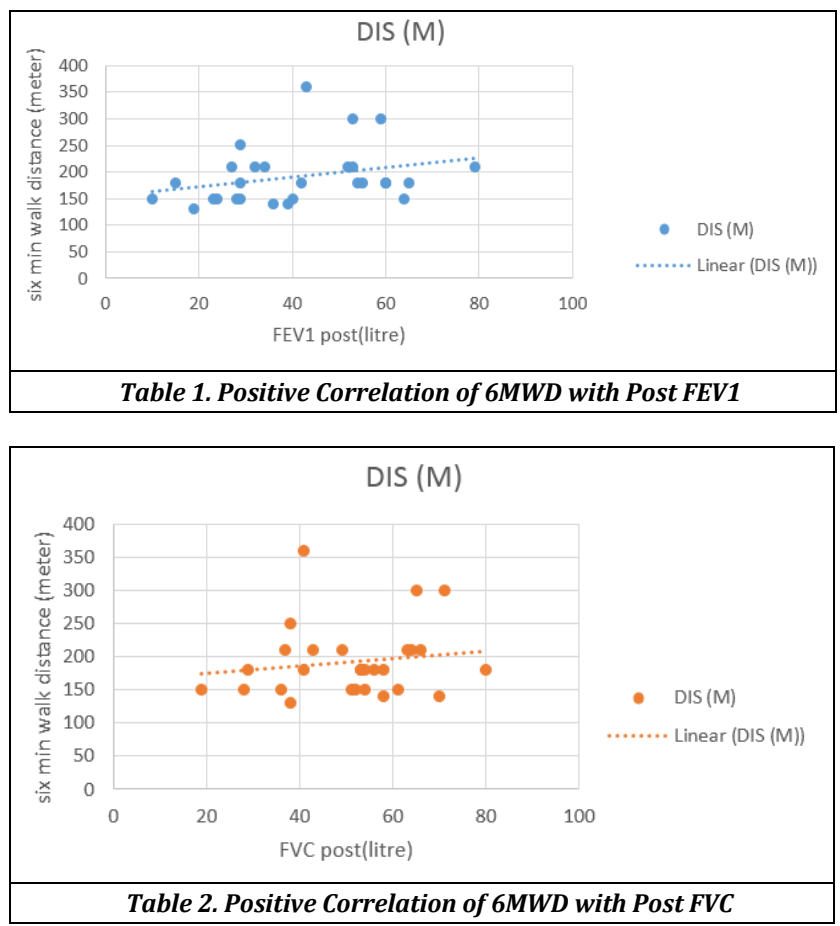
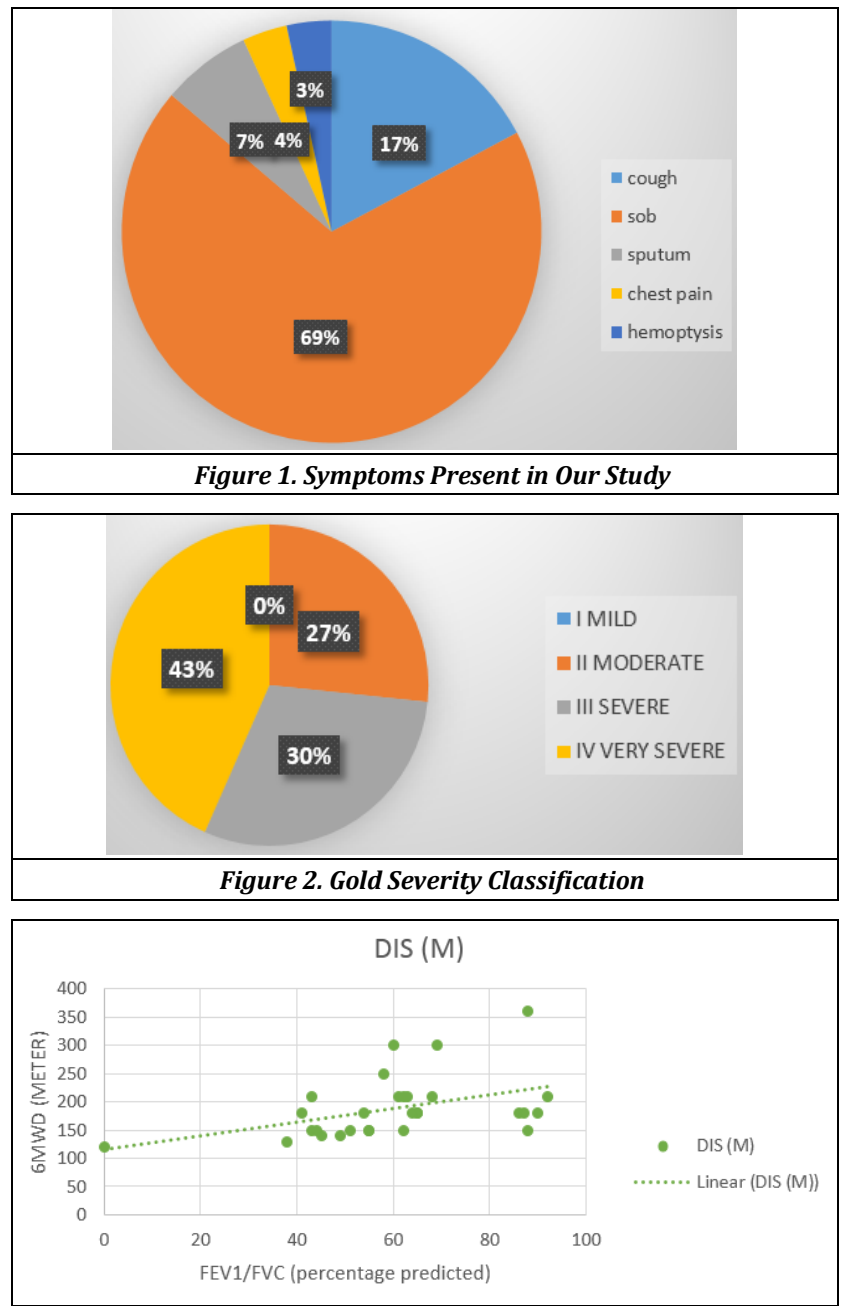

Table 3. Positive Correlation of 6MWD with FEV1/FVC

\begin{tabular}{|c|c|c|c|c|c|c|c|c|c|c|}
\hline \multicolumn{3}{|c|}{\begin{tabular}{|l|l|} 
\\
\end{tabular}} & \multicolumn{4}{|c|}{ Mean } & \multicolumn{4}{|c|}{ S.D. } \\
\hline \multicolumn{3}{|c|}{ FEV1/FVC(PR) } & \multicolumn{4}{|c|}{60.83} & \multicolumn{4}{|c|}{15.852} \\
\hline \multicolumn{3}{|c|}{ DIS (M) } & \multicolumn{4}{|c|}{189.31} & \multicolumn{4}{|c|}{54.963} \\
\hline \multicolumn{3}{|c|}{ DIS (M \%) } & \multicolumn{4}{|c|}{16831.03} & \multicolumn{4}{|c|}{5672.197} \\
\hline \multicolumn{3}{|c|}{ FEV1/FVC(PO) } & \multicolumn{4}{|c|}{62.36} & \multicolumn{4}{|c|}{16.292} \\
\hline \multicolumn{3}{|c|}{ FVC(PR) } & \multicolumn{4}{|c|}{48.03} & \multicolumn{4}{|c|}{14.443} \\
\hline \multicolumn{3}{|c|}{ FVC(PO) } & \multicolumn{4}{|c|}{51.00} & \multicolumn{4}{|c|}{14.466} \\
\hline \multicolumn{3}{|c|}{ FEV1(PR) } & \multicolumn{4}{|c|}{38.07} & \multicolumn{4}{|c|}{16.336} \\
\hline \multicolumn{3}{|c|}{ FEV1(PO) } & \multicolumn{4}{|c|}{41.18} & \multicolumn{4}{|c|}{17.282} \\
\hline \multicolumn{3}{|c|}{$\mathrm{HR}(\mathrm{PR})$} & \multicolumn{4}{|c|}{101.59} & \multicolumn{4}{|c|}{16.057} \\
\hline \multicolumn{3}{|c|}{$\mathrm{HR}(\mathrm{PO})$} & \multicolumn{4}{|c|}{111.52} & & & 2.557 & \\
\hline $\mathrm{SpC}$ & $2(\mathrm{PR})$ & & & & 2.03 & & & & .822 & \\
\hline $\mathrm{SpO}$ & 2(PO) & & & & 7.52 & & & & .315 & \\
\hline & & ble 4. & Mean & and $S$ & tande & $\operatorname{ard} \mathrm{De}$ & eviatio & & & \\
\hline & 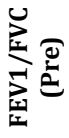 & 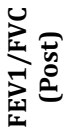 & ف & 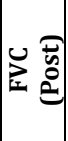 & $\begin{array}{ll}1 & 0 \\
11 & 0 \\
11 & 0\end{array}$ & 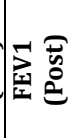 & 呈 巳 & 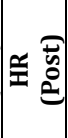 & $\mid \begin{array}{ll}0 & 0 \\
0 & 0 \\
\text { ñ } & 0\end{array}$ & $\mid \begin{array}{l}\tilde{0} \\
\text { की } \\
\text { के }\end{array}$ \\
\hline \begin{tabular}{|l|l|} 
& Pearson \\
$\Sigma$ & Correlation \\
\end{tabular} & $.444^{*}$ & .371 & .233 & .148 & $.384^{*}$ & .294 & -.311 & -.217 & .298 & $.383^{*}$ \\
\hline \begin{tabular}{c|c}
$\tilde{n}$ & Sig. \\
& $(2$-taied $)$ \\
\end{tabular} & .016 & .052 & .224 & .452 & .040 & 129 & .100 & .259 & .117 & .041 \\
\hline $\mathrm{N}$ & 29 & 28 & 29 & 28 & 29 & 28 & 29 & 29 & 29 & 29 \\
\hline \begin{tabular}{c|c|} 
& Pearson \\
& Correlation
\end{tabular} & $.384^{*}$ & .317 & .213 & .140 & .339 & .259 & -.252 & -.203 & .331 & $.427^{*}$ \\
\hline \begin{tabular}{c|c}
$\sum_{\curvearrowleft}$ & Sig. \\
(2-tailed)
\end{tabular} & .040 & .101 & .266 & .477 & .072 & .184 & .188 & .292 & .080 & .021 \\
\hline $\mathrm{N}$ & 29 & 28 & 29 & 28 & 29 & 28 & 29 & 29 & 29 & 29 \\
\hline $\begin{array}{l}\text { Correlation V } \\
0-\text { no correl } \\
0.1-0.3 \text { - wea } \\
0.4-0.6 \text { - mod } \\
0.7-0.9 \text { - stro } \\
1 \text { - Perfect co }\end{array}$ & $\begin{array}{l}\text { alues - } \\
\text { tion } \\
\text { k corre } \\
\text { erate c } \\
\text { ng corr } \\
\text { rrelatic } \\
\end{array}$ & $\begin{array}{l}\text { to +1; } \\
\text { tion } \\
\text { rrelatio } \\
\text { ation }\end{array}$ & & & & & & orre & & \\
\hline Table 5. & rel & $\begin{array}{l}\text { no } \\
P r\end{array}$ & ir & netr & Val & es $w$ & hix & Minu & $W c$ & Test \\
\hline
\end{tabular}




\section{DISCUSSION}

Chronic Obstructive Pulmonary Disease is a leading cause of morbidity and mortality worldwide and it has a definite social and economic impact. WHO (World health organization) predicted that Chronic Obstructive Pulmonary Disease will be the third leading cause of mortality and fifth leading cause of morbidity in 20201. Six Minute Walk Test is found to be an effective way of assessing exercise tolerance. There have been few studies correlating 6MWD with spirometry values in Chronic Obstructive Pulmonary Disease patients. For assessing the severity of COPD and there by staging the disease and treatment as per staging. Spirometry test is considered Gold standard but it is costly and is not available in many centers. Also it requires respiratory technician and is effort dependent.

Our study includes 30 COPD patients. The number of male and female patients were $90 \%$ and $10 \%$ respectively. Severity of the diseases was classified according to Global Initiative for chronic obstructive lung disease (GOLD) staging among the study population. $73 \%$ of our patients belong to stage 3 and stage 4 . The present study showed that FEV1 and FVC had very significant positive correlation with absolute as well as percent predicted six minute walk distance (6MWD). It meant the fall in FEV1 or FVC or both was associated with a significant fall in six minute walk distance. The study also showed positive correlation between Six Minute Walk Test and spirometry variables (FEV1 and FVC). The Six Minute Walk Test is a simple and easy to perform tool that provides assessment of functional exercise capacity in patient with COPD. Six Minute Walk Test is used to monitor the response to pharmacological and non-pharmacological therapy. It is also used for pre and post -operative evaluations in lung transplantation and lung volume reduction surgery. Six Minute Walk Test is used to predict the mortality and morbidity of patients with chronic respiratory disease like Interstitial Lung Disease, Chronic obstructive pulmonary disease, pulmonary hypertension. Simple method to look at the functional capacity of patients with COPD was introduced by Balke in $1963 .{ }^{6} \mathrm{He}$ had done it by measuring the total distance they could walk during a certain period of time. Butland et $\mathrm{al}^{7}$ improvised by proving that there was no significant difference between the Twelve Minute walk test (12MWT) and their Six Minute Walk Test in predicting the functional capacity of COPD patients.

Our study showed a positive linear correlation between Six Minute Walk Test and absolute values of spirometric indices FEV1, FVC and thus Six Minute Walk Test predicted severity of COPD in individual patients. Long -term follow-up in COPD patients by Casanova et al $^{8}$., in 2007 a longitudinal study showed that 6MWD decline by $19 \%$ over the 5yrs compared with baseline in patients in with GOLD 3 COPD (FEV1 $30-50 \%$ predicted) and by $26 \%$ in patients with GOLD4 COPD (FEV1<30\% predicted ). Our study showed that there was moderate positive correlation between the six minute walk distance and FEV1/FVC ration previously reported by other research too. The BODE index used to determine prognosis in Chronic Obstructive Pulmonary Disease patients. BODE index includes four variables (Body Mass Index, airway obstruction, dyspnoea, and exercise capacity). The BODE index contains a component each that quantifies obstructive disorder by FEV1 and that detects the perception of dyspnoea. The distance covered on the Six Minute Walk Test and BMI are two independent components which signifies the systemic consequences of Chronic Obstructive Pulmonary Disease. We found a significant negative correlation of Six Minute Walk Test with BODE index. If there was decrease in Six Minute Walk Test it was able to predict severity of COPD. Though BMI correlated well with severity of COPD as shown by Landbo et $\mathrm{al}^{9}{ }^{9}$ in their study, we did not find a strong correlation between BMI and Six-minute walk distance and this finding was comparable with the study done by Santana et al. ${ }^{10}$

\section{CONCLUSIONS}

Chronic Obstructive Pulmonary Disease is very common in clinical practice. It is diagnosed based on the clinical and spirometric data. Spirometry becomes insensitive tool for assessing the functional status in patients with severe airway obstruction who at times cannot perform spirometry. In such cases, Six Minute Walk Test plays an important role in assessing functional capacity. In this study, we demonstrated that Six-Minute Walk Test significantly correlated with spirometric absolute values of FEV1/FVC, FVC, FEV1. The variables of Six Minute Walk Test varied according to the severity of the disease. The six-minute walk distance and sixminute distance saturation both correlated with spirometry parameters FVC/FEV1 (moderately positive correlation or weak positive correlation) in severe and very severe COPD patients, and the $\mathrm{SpO}_{2}$ correlated with the scale. The predicted percent of FVC/FEV1 and FVC correlated with sixminute walk distance saturation in meters. Thus, we conclude that Six Minute Walk Test can replace spirometry in assessment of severity of COPD. But there are few limitations in our study such as no healthy person was taken as control and we could not compare 6MWD of study population with healthy control, Post bronchodilator Six Minute Walk Test was not done in our study; episodes of COPD exacerbation were not considered during study as it may have effect on Six Minute Walk Test.

\section{REFERENCES}

[1] Lozano R, Naghavi M, Foreman $K$, et al. Global and regional mortality from 235 causes of death for 20 age groups in 1990 and 2010: a systematic analysis for the Global Burden of Disease Study 2010. Lancet 2012;380(9859):2095-128.

[2] Jackson H, Hubbard R. Detecting chronic obstructive pulmonary disease using peak flow rate: cross sectional survey. BMJ 2003;327(7416):653-4.

[3] Pellegrino R, Viegi G, Brusasco V, et al. Interpretative strategies for lung function tests. Eur Respir J 2005;26(5):948-68.

[4] Solway S, Brooks D, Lacasse Y, et al. A qualitative systematic overview of the measurement properties of functional walk tests used in the cardiorespiratory 
domain. Chest 2001;119(1):256-70.

[5] Asmita M, Kumari IKS. Correlation of Six Minute Walk Test with Spirometry and DLCO in chronic respiratory diseases: a tertiary care hospital experience. Pulmon 2011;13(2):55-8.

[6] Balke B. A simple field test for the assessment of physical fitness. REP 63-6. Rep Civ Aeromed Res Inst US 1963:1-8.

[7] Butland RJ, Pang J, Groos ER, et al. Two, six and 12minute walking tests in respiratory disease. Br Med J (Clin Res Ed) 1982;284(6329):1607-8.

[8] Casanova C, de Torres JP, Aguirre-Jaime A, et al. The progression of chronic obstructive pulmonary disease is heterogeneous: the experience of the BODE cohort. Am J Respir Crit Care Med 2011;184(9):1015-21.

[9] Landbo C, Prescott E, Lange P, et al. Prognostic value of nutritional status in chronic obstructive pulmonary disease. Am J Respir Crit Care Med 1999;160(6):185661.

[10] Santana P, Cintra RM, Rodrigues F. Correlation study on the result from measures of function and functionality test of COPD patients. 2010. http://www.scriptiesonline.bib.hva.nl/documeny/1274 14. 